\title{
Evaluation of workload among industrial workers with the Need for Recovery Scale
}

\author{
Sobrecarga em trabalhadores da indústria avaliada por meio da escala de \\ necessidade de descanso
}

Cristiane S. Moriguchi', Michele E. R. Alem', Helenice J. C. G. Coury²

\begin{abstract}
Background: Work conditions can overload a worker's capabilities and result in health complaints. The early identification of hazardous work conditions allows the definition of priorities for more efficient ergonomic interventions. Objectives: To assess the need for recovery among industrial workers under different work conditions using the Need for Recovery Scale (NFR), and to verify the association between the scores and personal factors, occupational factors and daily activities. Methods: 191 workers (mean age of $34.5 \pm 8.3$ years) from a manufactory industry participated in this study. Workers answered both a questionnaire regarding demographic and occupational factors, and daily activities as well as the NFR. Ergonomic assessment of workplace sectors was carried out based on the Ergonomic Workplace Analysis. The Pearson chi-square test (significance level 5\%) was used to verify the association between NFR scores and the variables of interest. Results: The only association was between work sector and NFR score. According to the ergonomic assessment, the work sector with the highest need for recovery also presented the worst environmental and organizational conditions. Conclusions: The Need for Recovery Scale proved to be a helpful tool for differentiating work sectors presenting different workload demands and contributed to the definition of intervention priorities for preserving worker health.
\end{abstract}

Keywords: Fatigue; primary prevention; occupational health; occupational risks.

\section{Resumo}

Contextualização: As condições de trabalho podem gerar demandas excessivas e comprometer a saúde dos trabalhadores. A identificação precoce de condições críticas de trabalho permite determinar prioridades para intervenções preventivas e aumentar as chances de maior eficácia dessas medidas. Objetivos: Avaliar a necessidade de descanso para trabalhadores industriais submetidos a diferentes condições de trabalho utilizando a Escala de Necessidade de Descanso (ENEDE) e verificar a associação de seus resultados com fatores pessoais, ocupacionais e de hábitos cotidianos desses trabalhadores. Métodos: Participaram do estudo 191 trabalhadores (média de idade de 34,5 $\pm 8,3$ anos) de uma indústria de transformação de madeira. Os trabalhadores responderam a um questionário sobre dados demográficos, ocupacionais e de aspectos de vida cotidiana e à ENEDE. Realizou-se avaliação ergonômica dos setores de trabalho com base no protocolo Ergonomic Workplace Analysis. O teste qui-quadrado de Pearson a 5\% de significância foi utilizado para verificar associação entre a pontuação obtida pela ENEDE e os fatores avaliados. Resultados: Os resultados mostraram que houve associação apenas entre o setor de trabalho e as pontuações da ENEDE. Segundo a avaliação ergonômica, o setor que apresentou maior necessidade de descanso também apresentou piores condições de trabalho quanto a aspectos ambientais e organizacionais. Conclusões: A escala para avaliação da necessidade de descanso mostrou-se um instrumento útil para diferenciar setores de trabalho com diferentes níveis de exigências e contribuir para a definição de prioridades de intervenção para a preservação da saúde de trabalhadores industriais.

Palavras-chave: fadiga; prevenção primária; saúde do trabalhador; riscos ocupacionais.

Received: 27/04/2010 - Revised: 10/08/2010 - Accepted: 29/11/2010

${ }^{1}$ Postgraduate Program in Physical Therapy. Universidade Federal de São Carlos (UFSCar), São Carlos, SP, Brazil

${ }^{2}$ Physical Therapy Department, UFSCar

Correspondence to: Helenice Jane Cote Gil Coury, UFSCar, Departamento de Fisioterapia, Rodovia Washington Luís, Km 235, SP310, CEP 13565-905,. São Carlos, SP, Brasil,

e-mail: helenice@power.ufscar.br 


\section{Introduction $: \therefore$.}

Exposure to different working conditions may generate demands on workers that can result in both adaptation and work-related diseases ${ }^{1,2}$. Excessive demand may result in different consequences to worker health ${ }^{3}$. Extensive review studies have associated different physical, biomechanical and psychosocial/organizational risk factors with several physical and mental health hazards $s^{4-8}$.

Considering the diversity of existing occupational situations and the possible risk factors in each situation, tools that help identify ergonomic intervention priorities can be useful for health professionals involved in work-related disease control $^{9}$ since the earlier the identification, the more effective preventive interventions may be. A useful tool for such identification is the Need for Recovery Scale (NFR) ${ }^{10}$, which has been used to assess work-induced fatigue. It considers fatigue as a result of exposure to physical and mental demands imposed by work ${ }^{11,12}$

The role of the physical therapist in worker health is becoming increasingly widespread. One indication of this is the increasing number of researchers and related publications in Brazil and in Latin America ${ }^{13,14}$. Other indications include recognition of Occupational Physical Therapy as a specialty by the Federal Council of Physical Therapy and Occupational Therapy - COFFITO (Resolution No. 351, 2008) and the Brazilian Classification of Occupations by the Ministry of Labor and Employment ${ }^{15}$. Since the identification of risks in the workplace that may harm workers' health (Resolution No. 259, 2003 - COFFITO) is an important job requirement ${ }^{16}$, the physical therapist may employ different methods, such as questionnaires like the NFR, to assess the perceptual aspects of risk exposure.

Studies using the NFR have shown that high scores on the scale are associated with a higher incidence of work accidents ${ }^{17}$, health problems ${ }^{18}$ and absenteeism ${ }^{19}$. In this context, the NFR may be useful for the early identification of overload in workers. Furthermore, it has proven to be sensitive to organizational changes in the workplace, such as the implementation of activity rotation programs ${ }^{20}$ and increases in the number of hours worked ${ }^{21}$, which are important issues assessed by Organizational Ergonomics. Thus, the NFR can also be considered an important tool in planning and assessing preventive interventions in the workplace. For these reasons, the aim of the present study was to assess industrial workers' need for recovery under different work overloads using the NFR and to determine any association of its results with personal and occupational factors and daily habits.

\section{Methods : :}

\section{Subjects}

The study included 191 workers (mean age $34.5 \pm 8.3$ years) at a manufactory industry, of which 140 were women and 51 men. Only employees belonging to the two most numerous industry sectors (sectors A and B) and who had time available to answer the questionnaire were assessed. The workers from sector A were mainly machine operators who worked in groups of 2 to 4 and whose activities alternated between quality control of the final product, inspection of machine operation and material restocking. In sector B, most assessed workers worked with selecting materials and material assembly. On-the-job experience was $10.3 \pm 8.8$ years in sector $A$ and $5.5 \pm 5.9$ years in sector $\mathrm{B}$,

Worker participation was voluntary and affected neither wages nor overtime. All subjects were informed in advance about trial procedures and read and signed the consent form. The study was approved by the Ethics Committee on Human Research from the Universidade Federal de São Carlos (UFSCar), São Carlos, SP, Brazil (Proc. N. 0054.0.135.000.07).

\section{Procedures}

The workers answered a questionnaire containing demographic data (age, gender, educational level and marital status), occupational data (job function) and aspects of everyday life (housekeeping activities, smoking and physical activity practice) as well as the $\mathrm{NFR}^{10}$. The two occupational sectors in which participants worked were ergonomically assessed by an experienced physical therapist according to the Ergonomic Workplace Analysis (EWA) protocol, which was proposed by the Finnish Institute of Occupational Health $^{22}$.

Questionnaire responses were given at the workplace after the workers had been instructed on how to complete the questionnaire. The importance of accurate answers to the questions and the confidentiality of worker answers were also stressed.

\section{Assessment protocols}

The NFR is a self-explanatory questionnaire consisting of 11 multiple choice questions with four possible answers each. The total score ranges from 0 to 100; the higher the score, the greater the amount of emotional, cognitive and behavioral fatigue symptoms and the greater the need for worker recovery ${ }^{10}$. The cultural adaptation of the NFR into Brazilian Portuguese from English (Need for Recovery Scale) followed 
the procedures of systematic cultural translation of subjective tools ${ }^{10}$. The translated and culturally adapted version (NFR) showed psychometric parameters consistent for use with Brazilian workers ${ }^{10}$.

Ergonomic analysis of the work environment was based on Finnish Institute of Occupational Health ${ }^{22}$ guidelines, which cover 14 items: work space, general physical activity, lifting loads, work postures and movements, risk of accidents, work content, time constraints at work, communication between workers, decision making, repetitiveness of work, attention, lighting, thermal environment and noise. Each item received a score from the observer ranging from 1 to 5 . A score of 1 means that the assessed working condition is close to optimal (without risk), while a score of 4 or 5 indicates conditions potentially detrimental to worker health ${ }^{22}$.

\section{Data analysis}

Continuous variables (NFR scores and age) were categorized to enable implementation of the nonparametric test of association required by the other variables. For the NFR score obtained, a criterion of Kiss, de Meester e Braeckman ${ }^{23}$ was used to assess need for recovery level. This criterion divides scores into two categories: $\leq 45$ points and $>45$ points. The age variable was divided into three categories: $\leq 29$ years old, 30 to 39 , and 40 or older. The association between NFR scores, demographic and occupational variables and lifestyle habits was tested by the Pearson chi-square test at a 5\% significance level with SPSS v11.5 software. The results obtained by ergonomic analysis will be shown descriptively for comparison between sectors A and B.

\section{Results $: \because$.}

The association test showed that demographic factors and lifestyle habits were not associated with NFR scores (Table 1). Only the sector in which worker activities were performed influenced the need for recovery $(\mathrm{p}<0.001)$; sector A had the highest number of workers with scores above 45 .

While both sectors showed problems regarding physical items such as repetitiveness of work and work postures and movements, with slightly higher scores for sector B, sector A also showed organizational problems. The problems of this type for which sector A showed worse conditions than sector B were: time constraints at work, communication and personal contacts, thermal environment and noise. The major time constraints in sector A seem to have resulted from the fact that the work rate in most production processes is determined by the machine and not the worker. Thus, the worker has less freedom to control the time and mode of task execution, unlike sector B, where workers have greater control of the production process. Regarding communication and contact, sector A had more limited personal contact between workers due to the greater

Table 1. Workers categorized according to the Need for Recovery Scale scores and gender, housekeeping, physical activity, smoking, having children, work sector, age, educational level and marital status.

\begin{tabular}{|c|c|c|c|c|}
\hline$(p=0.39)$ & \multicolumn{4}{|c|}{ Gender } \\
\hline NFR & & Female & \multicolumn{2}{|c|}{ Male } \\
\hline$\leq 45$ & & 73 & \multicolumn{2}{|c|}{23} \\
\hline$>45$ & & 67 & \multicolumn{2}{|c|}{28} \\
\hline$(p=0.55)$ & \multicolumn{4}{|c|}{ Housekeeping activities } \\
\hline NFR & & Yes & \multicolumn{2}{|c|}{ No } \\
\hline$\leq 45$ & & 85 & \multicolumn{2}{|c|}{9} \\
\hline$>45$ & & 78 & \multicolumn{2}{|c|}{11} \\
\hline$(p=0.24)$ & \multicolumn{4}{|c|}{ Physical activity } \\
\hline NFR & & Yes & \multicolumn{2}{|c|}{ No } \\
\hline$\leq 45$ & & 45 & \multicolumn{2}{|c|}{49} \\
\hline$>45$ & & 35 & \multicolumn{2}{|c|}{54} \\
\hline$(p=0.56)$ & \multicolumn{4}{|c|}{ Smoking } \\
\hline NFR & & Yes & \multicolumn{2}{|c|}{ No } \\
\hline$\leq 45$ & & 9 & \multicolumn{2}{|c|}{84} \\
\hline$>45$ & & 11 & \multicolumn{2}{|c|}{78} \\
\hline$(p=0,33)$ & \multicolumn{4}{|c|}{ Children } \\
\hline NFR & & Yes & \multicolumn{2}{|c|}{ No } \\
\hline$\leq 45$ & & 54 & \multicolumn{2}{|c|}{39} \\
\hline$>45$ & & 58 & \multicolumn{2}{|c|}{31} \\
\hline$(p<0.001)$ & \multicolumn{4}{|c|}{ Work sector } \\
\hline NFR & & A & \multicolumn{2}{|c|}{ B } \\
\hline$\leq 45$ & & 26 & \multicolumn{2}{|c|}{60} \\
\hline$>45$ & & 53 & \multicolumn{2}{|c|}{34} \\
\hline$(p=0.68)$ & \multicolumn{4}{|c|}{ Age } \\
\hline NFR & $\leq 29$ years & $\begin{array}{c}30 \text { to } 39 \\
\text { years }\end{array}$ & \multicolumn{2}{|c|}{$\geq 40$ years } \\
\hline$\leq 45$ & 35 & 32 & \multicolumn{2}{|c|}{25} \\
\hline$>45$ & 29 & 35 & \multicolumn{2}{|c|}{27} \\
\hline$(p=0.76)$ & \multicolumn{4}{|c|}{ Educational level } \\
\hline NFR & $\begin{array}{l}\text { Primary } \\
\text { Education }\end{array}$ & $\begin{array}{l}\text { Secondary } \\
\text { Education }\end{array}$ & $\begin{array}{l}\text { Grac } \\
\text { tech }\end{array}$ & $\begin{array}{l}\text { Iated/ } \\
\text { ician }\end{array}$ \\
\hline$\leq 45$ & 7 & 76 & & 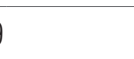 \\
\hline$>45$ & 9 & 69 & & 0 \\
\hline$(p=0.41)$ & & Marital s & & \\
\hline NFR & Single & Married & Divorced & Widower \\
\hline$\leq 45$ & 35 & 50 & 10 & 0 \\
\hline$>45$ & 28 & 52 & 8 & 2 \\
\hline
\end{tabular}


physical distance between workstations and greater noise intensity. Contact with supervisors occurs only indirectly, resulting in less technical and social support from management. In sector $\mathrm{B}$, communication was facilitated by the physical proximity of workstations, lower noise and more frequent contact with management, allowing greater interaction between workers and supervisors. Regarding environmental conditions, sector A was more exposed to seasonal temperature variations and higher noise levels due to the greater number of machines. The noise levels varied for sector A and B, respectively, from 78 to $89 \mathrm{~dB}$ and from 70 to $72 \mathrm{~dB}$.

\section{Discussion $: \because$.}

The results of this study showed that need for recovery levels were affected only by labor sector. The ergonomic analysis showed more critical biomechanical aspects in sector B and more critical environmental and organizational aspects in sector A. Although the biomechanical risk factors in sector $\mathrm{B}$ are known to be associated with the development of workrelated diseases, they do not seem to have substantially affected worker need for recovery when compared to the more critical organizational factors identified in sector A.

This may be due to the greater influence of the psychological rather than the physical demands of the work environment on NFR scores, although both reflect fatigue intensity ${ }^{12}$. Another aspect to consider is that the concept of fatigue assessed by the NFR is based on the Effort-Recovery Model proposed by Meijman ${ }^{12}$. According to this model, the effect of overload on the worker is influenced by both work and individual characteristics. Among the work characteristics, work control has a major influence on the need for recovery, because the level of control determines the worker's chance of recovery ${ }^{24}$.

The temperature variations and high level of noise found in sector A may also have contributed to the high NFR scores. According to Parsons ${ }^{25}$, heat stress and high noise levels can generate greater overload for the individual as well as feelings of discomfort, health effects and decreased worker performance.

In the present study, there was no association between gender and NFR scores. The fact that both genders reported housekeeping activities may have contributed to the lack of gender difference. Nevertheless, whether due to this or other related variables, the fact is that studies still differ on the influence of gender on worker need for recovery ${ }^{11,23,26}$. According to a literature review ${ }^{27}$, a greater observed susceptibility to illness by a certain gender should be viewed with caution, since differences in exposure may lead to overestimations ${ }^{28}$.
Leisure-time physical activity levels also showed no association with worker need for recovery, despite the known benefits of physical activity on quality of life and well-being ${ }^{29}$. One factor that may have influenced this result is the company's daily employee exercise program, which is similar in both sectors and includes warm-up exercises at the beginning of the shift and two breaks for stretching. The link between on-the-job exercise and relief of physical and mental fatigue has been recognized ${ }^{30}$. However, further studies are needed to confirm this hypothesis.

Neither smoking nor educational level influenced the intensity of need for recovery. In both cases, the shape of data distribution may have influenced the results, since most workers were non-smokers and had completed high school. Studies with a wide distribution of individuals among different educational categories should be conducted to better assess the association between these factors and NFR.

The presence or absence of children did not influence the intensity of worker need for recovery. Although some association could be expected, these results are consistent with the findings of Kiss, Meester and Braeckman ${ }^{23}$. According to these authors, having one or more children at home does not increase the chance of having higher scores on the scale than workers with no children.

The lack of association between age and higher NFR scores differs from the results of Kiss, Meester and Braeck$\operatorname{man}^{23}$, who found differences between younger and older workers in a public sector. One possible reason for this is that more young workers were analyzed, with relatively few workers over 45 years of age. Despite the lack of association between age and level of need for recovery reported here, age is a factor to be considered in such assessments, since older workers tend to have higher rates of need for recovery ${ }^{19,31}$.

Marital status was also not associated with NFR scores. Only one study in the literature (by Croon, Sluiter and FringsDresen $)^{19}$ has reported that divorced individuals in large companies with high scores on the scale showed a greater tendency toward future absenteeism. Nevertheless, Croon, Sluiter and Frings-Dresen ${ }^{19}$ did not assess the relationship between NFR and marital status.

Regarding the methodological aspects of the scale, no NFR score cutoff points have been established in the literature for identifying workers at risk of developing health problems, although cutoffs of 45 and 50 have been suggested ${ }^{23,31}$. Another study used the distribution of data itself to identify workers most in need for recovery and found that workers with scores corresponding to the upper quartile were those that had the most fatigue ${ }^{26}$.

The results of the present study are limited to industrial workers and, therefore, cannot be generalized to other 
populations. Further studies that analyze a larger number of workers performing more diversified occupational activities at different intensities are needed in order to comparatively assess the results of NFR in these populations.

It is also important to note that NFR is a tool that should be used by health professionals to benefit the worker and not as a means of hiring discrimination. Another point to consider is that the use of the NFR allows the identification of worker overload conditions, but does not directly suggest resolutions for the identified problem. The proposal of effective intervention measures is a task that requires specific training in worker health areas, such as Ergonomics and Occupational Physical Therapy. The NFR can be seen as one more tool for identifying risks ${ }^{11}$ and, thus, can help determine priorities for ergonomic intervention. It can also serve as a tool for assessing and comparing pre- and post-intervention conditions ${ }^{20,21}$.

\section{Conclusion $: \because$.}

The NFR proved to be a sensitive tool for assessing the need of recovery for workers under different working conditions, enabling a comparative analysis between different levels of occupational activities, and thus it could be an important tool for occupational health professionals. More studies using the NFR are needed to better define the cutoff points for need-for-recovery categories, as well as to investigate the clinical outcome in other worker populations.

\section{Acknowlegments : :}

To the Fundação de Amparo à Pesquisa do Estado de São Paulo (FAPESP) protocol No. 2008/10399-0.

\section{References: : :}

1. Westgaard RH, Winkel J. Guidelines for occupational musculoskeletal load as a basis for intervention: a critical review. Appl Ergon. 1996;27(2):79-88.

2. Kowalski C, Driller E, Ernstmann N, Alich S, Karbach U, Ommen O, et al. Associations between emotional exhaustion, social capital, workload, and latitude in decisionmaking among professionals working with people with disabilities. Res Dev Disabil. 2010;31(2):470-9. Epub 2009 Dec 8.

3. Forde MS, Punnett L, Wegman DH. Pathomechanisms of work-related musculoskeletal disorders: conceptual issues. Ergonomics. 2002;45(9):619-30.

4. Bernard B. Musculoskeletal Disorders and Workplace Factors: A critical review of epidemiologic evidence for work-related musculoskeletal disorders of the neck, upper extremity, and low back. Cincinnati: National Institute for Occupational Safety and Health, Publications Dissemination, Publication No. 97-141; 1997.

5. Bongers PM, Kremer AM, ter Laak J. Are psychosocial factors, risk factors for symptoms and signs of the shoulder, elbow, or hand/wrist? A review of the epidemiological literature. Am J Ind Med. 2002;41(5):315-42.

6. Côté P, Van der Velde G, Cassidy JD, Carroll LJ, Hogg-Johnson S, Holm LW, et al. The burden and determinants of neck pain in workers: results of the bone and joint decade 2000-2010 task force on neck pain and its associated disorders. Spine (Phila Pa 1976). 2008;33(4 Suppl): S60-74.

7. Netterstrøm B, Conrad N, Bech P, Fink P, Olsen O, Rugulies R, et al. The relation between work-related psychosocial factors and the development of depression. Epimemiol Rev. 2008;30:118-32. Epub 2008 Jun 27.

8. Nora (Organization of Work Team Members). The changing organization of work and the safety and health of working people (DHHS Publication $N^{\circ}$ 2002-116). National Institute for Occupational Safety and Health, Cincinnati, $\mathrm{OH}$.

9. Silverstein BA, Stetson DS, Keyserling WM, Fine LJ. Work-related musculoskeletal disorders: comparison of data sources for surveillance. Am J Ind Med. 1997;31(5):600-8.

10. Moriguchi CS, Alem MER, van Veldhoven M, Coury HJCG. Cultural adaptation and psychometric properties of Brazilian Need for Recovery Scale. Rev Saúde Pública. 2010;44(1):131-9.

11. Sluiter JK, de Croon EM, Meijman TF, Frings-Dresen MH. Need for recovery from work related fatigue and its role in the development and prediction of subjective health complaints. Occup Environ Med. 2003;60(Suppl 1):i62-70.

12. van Veldhoven M, Broersen S. Measurement quality and validity of the "need for recovery scale". Occup Environ Med. 2003;60(Suppl 1):i3-9.

13. Coury HJCG. Time trends in ergonomic intervention research for improved musculoskeletal health and comfort in Latin American. Appl Ergon. 2005:36(2):249-52.
14. Coury HJCG, Vilella I. Profile of the Brazilian physical therapy researcher. Rev Bras Fisioter. 2009;13(4):356-63.

15. Baú LM, Klein AA. 0 reconhecimento da especialidade em fisioterapia do trabalho pelo COFFITO e Ministério do Trabalho/CBO: Uma conquista para a fisioterapia e a saúde do trabalhador. Rev Bras Fisioter. 2009;13(2):v-vi.

16. Jones T, Kumar S. Physical ergonomics in low-back pain prevention. J Occup Rehabil 2001;11(4):309-19.

17. Swaen GM, van Amelsvoort LG, Bültmann U, Kant IJ. Fatigue as a risk factor for being injured in an occupational accident: results from the Maastricht Cohort Study. Occup Environ Med. 2003;60(Suppl 1):i88-92.

18. Sluiter JK, van der Beek AJ, Frings-Dresen MH. The influence of work characteristics on Ergonomics the need for recovery and experienced health: a study on coach drivers 1999;42(4):573-83.

19. de Croon EM, Sluiter JK, Frings-Dresen MH. Need for recovery after work predicts sickness absence: a 2-year prospective cohort study in truck drivers. J Psychosom Res. 2003;55(4):331-9

20. Kuijer PP, van der Beek AJ, van Dieën JH, Visser B, Frings-Dresen MH. Effect of job rotation on need for recovery, musculoskeletal complaints, and sick leave due to musculoskeletal complaints: a prospective study among refuse collectors. Am J Ind Med. 2005;47(5): 394-402.

21. de Croon EM, Sluiter JK, Frings-Dresen MH. Psychometric properties of the Need for Recovery after work scale: test-retest reliability and sensitivity to detect change. Occup Environ Med. 2006;63(3):202-6.

22. Ahonen M, Launis $M$, Kuorinka $T$ (Editores). Ergonomic workplace analysis. Finlândia: Finnish Institute of Occupational Health; 1989

23. Kiss $P$, de Meester $M$, Braeckman L. Differences between younger and older workers in the need for recovery after work. Int Arch Occup Environ Health. 2008;81(3):311-20. Epub 2007 Jun 19.

24. van Veldhoven M. Need for recovery: an overview of concept, measurement and research In: Houdmont J, Lexa S. (Eds.). Occupational health psychology: European perspectives on research, education and practice. $3^{\mathrm{a}}$ ed. Castelo de Maia: Nottingham University Press; 2008. p. 1-25.

25. Parsons KC. Environmental ergonomics: a review of principles, methods and models. Appl Ergon. 2000;31(6):581-94.

26. Jansen NW, Kant IJ, van den BrandtPA. Need for recovery in the working population: description and associations with fatigue and psychological distress. Int J Behav Med. 2002;9(4): $322-40$. 
27. Hooftman WE, van Poppel MN, van der Beek AJ, Bongers PM, van Mechelen W. Gender differences in the relations between work-related physical and psychosocial risk factors and musculoskeletal complaints. Scand J Work Environ Health. 2004;30(4):261-78.

28. Coury HJCG, Walsh IAP, Alem MER, Oishi J. Influence of gender on work-related musculoskeletal disorders in repetitive tasks. Int J Ind Ergon. 2002;29(1):33-9.

29. Atlantis E, Chow CM, Kirby A, Singh MF. An effective exercise-based intervention for improving mental health and quality of life measures: a randomized controlled trial. Prev Med. 2004;39(2):424-34

30. Proper KI, Koning M, van der Beek AJ, Hildebrandt VH, Bosscher RJ, van Mechelen W. The effectiveness of worksite physical activity programs on physical activity, physical fitness, and health. Clin J Sport Med. 2003:13(2):106-17.

31. Kiss P, de Meester M. Need for recovery in ageing workers. Int Congr Ser. 2005;1280:202-7. 